\title{
In Vitro Screening of 10 Edible Thai Plants for Potential Antifungal Properties
}

\author{
Supattra Suwanmanee, ${ }^{1}$ Thitinan Kitisin, ${ }^{2}$ and Natthanej Luplertlop ${ }^{3}$ \\ ${ }^{1}$ Department of Tropical Pathology, Faculty of Tropical Medicine, Mahidol University, Bangkok 10400, Thailand \\ ${ }^{2}$ Department of Anatomy, Faculty of Science, Mahidol University, Bangkok 10400, Thailand \\ ${ }^{3}$ Department of Microbiology and Immunology, Faculty of Tropical Medicine, Mahidol University, Bangkok 10400, Thailand
}

Correspondence should be addressed to Natthanej Luplertlop; natthanej.lup@mahidol.ac.th

Received 22 August 2013; Revised 26 November 2013; Accepted 26 November 2013; Published 2 January 2014

Academic Editor: Angelo Antonio Izzo

Copyright (C) 2014 Supattra Suwanmanee et al. This is an open access article distributed under the Creative Commons Attribution License, which permits unrestricted use, distribution, and reproduction in any medium, provided the original work is properly cited.

\begin{abstract}
Growing rates of fungal infections and increasing resistance against standard antifungal drugs can cause serious health problems. There is, therefore, increasing interest in the potential use of medicinal plants as novel antifungal agents. This study investigates the antifungal properties of crude plant extracts from ten medicinal plant species. Crude samples were extracted using the hot water extraction process. The minimum inhibitory concentrations (MIC) and diameter zone of inhibition were determined in each extract against ten fungal strains, and fluconazole was used as a positive control. The cytotoxicity of crude extracts on in vitro human skin fibroblast (HSF) cell models was determined by MTT assay. Of the ten crude extracts, Psidium guajava L. exhibited the highest antifungal activity, diameter zone of inhibition, and percentage HSF cell viability. Although all extracts exhibited antifungal activity, Psidium guajava $L$. had the greatest potential for developing antifungal treatments.
\end{abstract}

\section{Introduction}

Despite the intensive prophylactic use of antifungal drugs, the incidence of fungal infections has increased due to growing resistance $[1,2]$. Therefore, the possibility of finding novel antifungal agents from crude plant extracts has been explored. Many edible plants are known to have beneficial and medicinal properties to humans, and plant extracts have been used as a source of alternative medication for their antioxidative, antifungal, and anticancer properties [3].

Ten plants commonly used in Thai traditional medicine were selected for this study: Garcinia mangostana L., Piper betel L., Camellia sinensis, Morus alba Linn., Aegle marmelos L., Garcinia atroviridis Griff., Andrographis paniculata (Burm.f.) Wall.ex Nees, Schefflera leucantha R. Vig., Carthamus tinctorius L., and Psidium guajava L. The objective of this study was to evaluate the in vitro antifungal activities of crude extracts of these edible plant species in a systematic and consistent manner against clinical pathogens. The results indicate that there are potential benefits of using crude plant extracts for the treatment of fungal infections.

\section{Materials and Methods}

2.1. Preparation of Plant Sample Extracts. The ten plant species used in this study can be divided into four categories according to their active ingredients. The first category is condensed tannins, which is obtained from the peel of Garcinia mangostana L. (mangosteen). The second is hydrolysable tannins, obtained from the leaf of Piper betel L. (betel vine) and Camellia sinensis (green tea). The third category is flavonols, obtained from the leaf of Morus alba Linn. (mulberry). The fourth category is phenols, obtained from the fruit of Aegle marmelos L. (bael) and Garcinia atroviridis Griff (Malabar tamarind), from the leaf of Andrographis paniculata (Burm.f.) Wall.ex Nees (create), Schefflera leucantha R. Vig. (edible-stemmed vine), and Psidium guajava L. (guava), and from the flower of Carthamus tinctorius L. (safflower) (Table 1). All plant samples were provided by the Faculty of Cosmetic Science, Mae Fah Luang University, and were collected from northern Thailand, Chiang Rai province. The crude plant extraction process was performed according to AOAC procedures, with some modifications [4]. $100 \mathrm{~g}$ of each 
TABLE 1: List of plant species and parts of the plant used to determine antifungal activity as crude plant extracts obtained by hot water extraction process.

\begin{tabular}{|c|c|c|c|c|}
\hline Active ingredient & Group & Plant species with ref. & General name & Part used \\
\hline \multirow{3}{*}{ Tannins } & Condensed tannins & Garcinia mangostana L. [5] & Mangosteen & Peel \\
\hline & \multirow{2}{*}{ Hydrolysable tannins } & Piper betel L. [6] & Betel vine & Leaf \\
\hline & & Camellia sinensis [7] & Green tea & Leaf \\
\hline Flavonoids & Flavonols & Morus alba Linn. [8] & Mulberry & Leaf \\
\hline \multirow{6}{*}{ Phenol } & \multirow{6}{*}{ Phenol } & Aegle marmelos L. [9] & Bael & Fruit \\
\hline & & Garcinia atroviridis Griff. [5] & Malabar tamarind & Fruit \\
\hline & & Andrographis paniculata (Burm.f.) Wall.ex Nees [10] & Create & Leaf \\
\hline & & Schefflera leucantha R. Vig [11] & Edible-stemmed Vine & Leaf \\
\hline & & Carthamus tinctorius L. [12] & Safflower & Flower \\
\hline & & Psidium guajava L. [13-15] & Guava & Leaf \\
\hline
\end{tabular}

TABLE 2: Clinical human pathogenic fungal strains used in this study.

\begin{tabular}{lc}
\hline Type & Name \\
\hline Yeast & Candida albicans \\
& Saccharomyces cerevisiae \\
\hline & Trichophyton mentagrophytes \\
& Trichophyton rubrum \\
& Trichophyton tonsurans \\
Dermatophytes & Epidermophyton floccosum \\
& Microsporum canis \\
& Microsporum gypseum \\
\hline \multirow{2}{*}{ Filamentous fungi } & Aspergillus niger \\
& Penicillium spp. \\
\hline
\end{tabular}

plant sample was dried, powdered, macerated, and extracted by hot water extraction process. Subsequently, all crude extracts underwent sterile filtering by using a $0.22 \mu \mathrm{m}$ sterile filter. All sterile filtered crude extracts were stored at $-20^{\circ} \mathrm{C}$. The crude extracts were later thawed and serial dilutions were prepared by using Sabouraud Dextrose Broth (SDB) media.

2.2. Fungal Strains and Growth Conditions. Fungal isolates were subcultured and prepared for assessment of the antifungal properties of the plant extracts. All fungal strains used in this study were provided by the Department of Microbiology and Immunology, Faculty of Tropical Medicine, Mahidol University, Thailand. The fungi can be divided into 3 groups. The first group is yeasts, which include Candida albicans and Saccharomyces cerevisiae. The second is dermatophytes, which include Trichophyton mentagrophytes, Trichophyton rubrum, Trichophyton tonsurans, Epidermophyton floccosum, Microsporum canis, and Microsporum gypseum. The third group is filamentous fungi, which include Aspergillus niger and Penicillium spp. All fungi were cultured in Sabouraud agar slants or Sabouraud Dextrose Broth (SDB). The clinical fungal strains used in this study are listed in Table 2. The yeasts were each diluted in SDB broth to a concentration of $10^{6} \mathrm{CFU} / \mathrm{mL}$. This was further diluted with RPMI to $2 \times$ $10^{5} \mathrm{CFU} / \mathrm{mL}$, and $100 \mu \mathrm{L}$ was then added to each of the serial dilutions of the plant extracts. $100 \mu \mathrm{L}$ of each dilution was then added to the serial dilutions of the plant extracts.

2.3. Antifungal Activity. The screening of plant extracts for antifungal activity was investigated using a modified broth microdilution method. The plant extract/fungal isolate microtiter trays were stored at $35^{\circ} \mathrm{C}$ and assessed for growth after $48 \mathrm{~h}$. The antifungal agents were prepared for minimum inhibitory concentration (MIC), according to Clinical and Laboratory Standards Institute (CLSI-formerly NCCLS) [16, 17] with RPMI-MOPS (RPMI 1640 medium containing 1glutamine, without sodium bicarbonate (Sigma-Aldrich Co., St. Louis, USA) buffered to $\mathrm{pH} 7.0$ with $0.165 \mathrm{~mol} / \mathrm{L}$ MOPS buffer-Sigma). The SDB media were used as negative control, and fluconazole $(1 \mathrm{mg} / \mathrm{mL})$ was used as positive control. MIC was represented as the lowest concentration of compounds at which the microorganism tested did not demonstrate visible growth. The experiments were carried out in triplicate. Inhibition (\%) was calculated as follows:

$$
\text { Inhibition }(\%)=\left[\frac{(\mathrm{DC}-\mathrm{DE})}{\mathrm{DC}}\right] \times 100 \text {, }
$$

where DE is the diameter of growth zone in experimental disc $(\mathrm{cm})$ and DC is the diameter of the growth zone in the control $\operatorname{disc}(\mathrm{cm})$.

2.4. Human Skin Fibroblast (HSF) Cell Preparation. Human skin fibroblast (HSF) cells were maintained in Dulbecco's modified minimum essential medium (DMEM, Gibco, USA), supplemented with $10 \%$ heat-inactivated $\left(56^{\circ} \mathrm{C}\right.$ for $30 \mathrm{~min}$ ) fetal bovine serum (FBS, Hycone, USA), 1\% L-glutamine, and $1 \%$ antibiotics $(200 \mathrm{U} / \mathrm{mL}$ penicillin and $100 \mu \mathrm{g} / \mathrm{mL}$ of streptomycin, Gibco, USA) at $37^{\circ} \mathrm{C}$ with $5 \%$ concentration of $\mathrm{CO}_{2}$ incubator. The cells were detached from the surface using 0.25\% trypsin/EDTA (PAA Laboratories GmbH, Austria).

\subsection{Effect of Plant Extracts on Cell Viability (MTT) on Human} Skin Fibroblast (HSF) Cells. The colorimetric MTT assay used was similar to that originally described by Mosmann [18]. The assay was based on the ability of mitochondria to reduce MTT, a yellow tetrazolium dye, to MTT formazan, a 
blue mitochondrial byproduct. The reduction is mediated by mitochondrial dehydrogenases that are present in living but not dead cells.

HSF cells were cultured in 96-well cell-culture plates with a cell concentration of $1.0 \times 10^{5}$ cells $/ \mathrm{mL} .200 \mu \mathrm{L}$ of the diluted cell suspension transferred to each well. The cells were treated with $200 \mu \mathrm{L}$ of crude plant extract samples. Fluconazole was used as positive control and SDB as negative control at $37^{\circ} \mathrm{C}$ for 24 hours, in triplicate, followed by cell washing. $20 \mu \mathrm{L}$ of MTT $(0.1 \mathrm{mg} / \mathrm{mL})$ solution was added to each well. After 4 hours, the supernatant was aspirated and $150 \mu \mathrm{L}$ of DMSO was added to each well; then, the cells were incubated at $37^{\circ} \mathrm{C}$ for 10 minutes. The absorbance at $570 \mathrm{~nm}$ was then read for each well to determine cell viability. The lethal dose of cytotoxic concentration from crude plant extract samples was expressed as $50 \%$ cellular mitochondrial activity, $\mathrm{LD}_{50}$ $(\mathrm{mg} / \mathrm{mL})$ and was obtained by interpolation from linear regression analysis.

2.6. Statistical Analysis. All assays were conducted in triplicate and unpaired $t$-tests of independent experiments were performed by statistical analysis using GraphPad Prism 6 program version 6.02 (Trial) (Statcon). Results were considered significant at $P$ value $\leq 0.05$.

\section{Results and Discussion}

The results of our antifungal activity analysis revealed that the MIC values from crude plant extracts varied from $2.67 \mathrm{mg} / \mathrm{mL}$ to $128 \mathrm{mg} / \mathrm{mL}$. Different fungal strains exhibited different levels of sensitivity to each crude plant extract. Table 3 indicates that crude extracts from Psidium guajava L. exhibited the highest antifungal activity, diameter zone of inhibition, $\mathrm{LD}_{50}$, and percent $\mathrm{HSF}$ cell viability, while Aegle marmelos L. exhibited the lowest activity compared to the other plants (Psidium guajava L. > Piper betel L. > Schefflera leucantha R. Vig > Andrographis paniculata (Burm.f.) Wall.ex Nees > Garcinia atroviridis Griff > Morus alba Linn. > Garcinia mangostana L. > Carthamus tinctorius L. > Camellia sinensis $>$ Aegle marmelos L.).

Psidium guajava L. crude extracts were extracted from the plant's leaves. Previous studies have found that Psidium guajava L. leaves have high levels of essential oils, primarily $\beta$-pinene, $\alpha$-pinene, limonene, menthol, terpenyl acetate, isopropyl alcohol, longicyclene, caryophyllene, $\beta$-bisabolene, cineol, caryophyllene oxide, $\beta$-copanene, farnesene, humulene, selinene, cardinene, and curcumene [13, 14]. High quantities of flavonoids and triterpenoids were also found [15]. In addition to these active compounds found in Psidium guajava L., this study found that Psidium guajava L. crude extracts exhibited the highest antifungal activity of the plants tested (Table 3), supporting previous studies of the plant's beneficial properties [19-22].

Piper betel L. crude extracts, also obtained from the leaf, showed the second highest antifungal activity compared with the other plants tested (Table 3). A preliminary study has reported that Piper betel L. leaf extract contains a large number of bioactive molecules, including polyphenols, alkaloids, steroids, saponins, and hydrolysable tannins [6]. The crude extracts containing these active ingredients exhibited fungal cytotoxicity against all fungal strains tested, supporting previous investigations [23].

Schefflera leucantha R. Vig crude (leaf) extracts showed the third highest antifungal activity compared with the other plants (Table 3). It has been reported that the active compound found in the crude extract is a mixture of saponins [11].

Andrographis paniculata (Burm.f.) Wall.ex Nees (leaf) extracts contain phytochemicals such as DL-limonene and euasarone [10].

Atroviridin, garcinia acid, and $\gamma$-lactone were major active compounds found in Garcinia atroviridis Griff (fruit) extracts [5].

Papyriflavonol A, kuraridin, sophoraflavanone D and sophoraisoflavanone A were previously identified as antifungal compounds found in Morus alba Linn (leaf) extracts [8].

$\alpha$-Mangostin was a major antifungal compound found in Garcinia mangostana L. (peel) extracts [24].

Coumaroylspermidine was found in Carthamus tinctorius $\mathrm{L}$. (flower) extracts and reportedly has antifungal activity [12].

The active catechin compounds were the most beneficial effects from Camellia sinensis (leaf) extracts [7], which exhibited antifungal and anti bacterial activities [25].

Aegelenine and aegeline, phlobatannins, flavan-3-oil, leucoanthocyanins anthocyanins, flavonoid glycosides, skimmianine, $\beta$-sitosterol, rutin, and marmesinin have been found in leaf extracts of Aegle marmelos L., which exhibited antifungal activity [9].

Interestingly, our study shows that the highest antifungal activity derived from crude extracts containing active ingredients found in the leaf (such as Psidium guajava L. and Piper betel L.). However, one should note that the phytochemical properties from extracts in this study may vary depending on ecological and geographical conditions, age of plant, and time of harvesting. The exact level of active compound concentration in each extract also requires further study, as this information may provide valuable data for large-scale production of crude plant extracts with antifungal properties.

The high function of phenols in Psidium guajava L. crude extract exhibited an antioxidative property, which was reflected in high $\mathrm{LD}_{50}(3.50 \mathrm{mg} / \mathrm{mL})$ compared with other crude plant extracts (Table 3 ). These data indicate that a high $\mathrm{LD}_{50}$ concentration value results in strong antifungal properties, and as determined by HSF cells in vitro, is also safe for application as a topical treatment. Psidium guajava L. crude extract, previously reported for antioxidative activity, [13-15] showed high \% HSF cell viability (93\%) (Table 3) compared with other plants and fluconazole (antifungal drug; $\mathrm{LD}_{50}, 1.00 \mathrm{mg} / \mathrm{mL}$ and cell viability, $86 \%$ ). This suggests that phenols found in crude plant extracts, particularly in Psidium guajava L., not only exhibit antifungal activity but also prevent cellular damage and oxidative injuries arising from free radicals or reactive oxygen species (ROS) [26]. This may be a promising result leading to safer antifungal agents for use on human skin.

Our findings show that all the crude plant extracts studied were effective antifungal agents. However, the phenol-based 


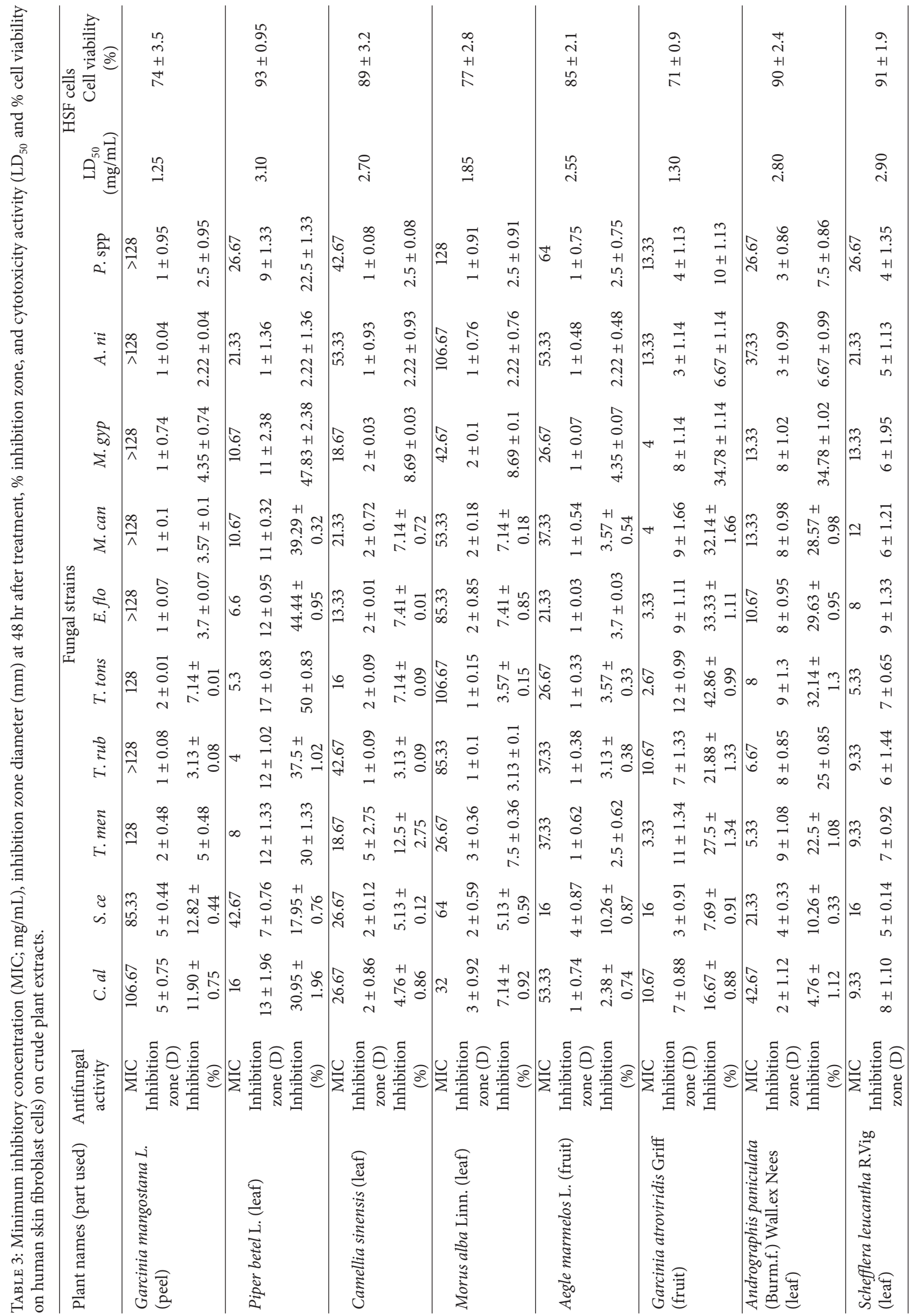




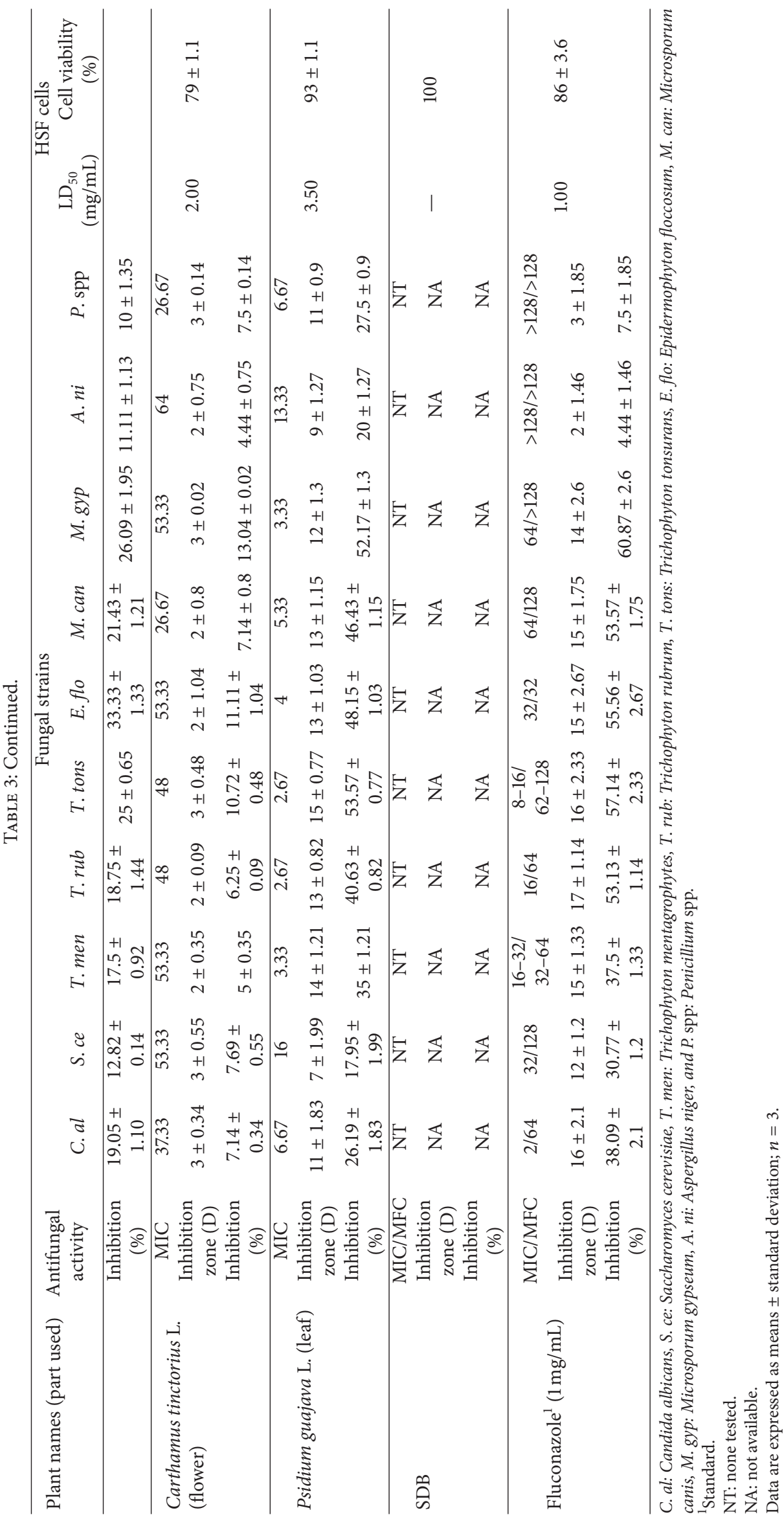


group exhibited the highest activity and may also help prevent cellular damage from oxidative stress through its antioxidative property, represented by high \% cell viability.

\section{Conclusion}

Our study investigated the role of ten selected crude plant extracts and their antifungal activity. Among them, the phenol crude extract group exhibited outstanding results (particularly Psidium guajava L.). Our findings suggest an alternative way to utilize crude plant extracts as their antifungal activity and antioxidative properties may alleviate these pathogenic infections. However, further studies are needed, particularly on the properties of crude plant extracts on immunomodulation against fungi, the reduction of fungal infection-induced inflammatory cytokine after crude plant extract treatment both in vitro and in vivo, and the formulation of cosmetic products using active ingredient from plant extracts.

\section{Conflict of Interests}

The authors have declared that there is no conflict of interests.

\section{Acknowledgments}

This study was supported by a Trop. Med. grant and Dean's Fund grant, 2012, Faculty of Tropical Medicine, Mahidol University, Bangkok, Thailand.

\section{References}

[1] A. C. Stein, M. Sortino, C. Avancini, S. Zacchino, and G. Von Poser, "Ethnoveterinary medicine in the search for antimicrobial agents: antifungal activity of some species of Pterocaulon (Asteraceae)," Journal of Ethnopharmacology, vol. 99, no. 2, pp. 211-214, 2005.

[2] L. Svetaz, F. Zuljan, M. Derita et al., "Value of the ethnomedical information for the discovery of plants with antifungal properties. A survey among seven Latin American countries," Journal of Ethnopharmacology, vol. 127, no. 1, pp. 137-158, 2010.

[3] D. Webster, P. Taschereau, R. J. Belland, C. Sand, and R. P. Rennie, "Antifungal activity of medicinal plant extracts; preliminary screening studies," Journal of Ethnopharmacology, vol. 115, no. 1, pp. 140-146, 2008.

[4] Association of Official Analysis Chemists, Official Method of Analysis of the AOAC International, AOAC, Arlington, Va, USA, 16th edition, 1995.

[5] J. Kosin, N. Ruangrungsi, C. Ito, and H. Furukawa, "A xanthone from Garcinia atroviridis," Phytochemistry, vol. 47, no. 6, pp. 1167-1168, 1998.

[6] R. S. Koff, G. Gordan, and S. M. Sabesin, "D-Galactosamine hepatitis hepatocellular injury and fatty liver following a single dose," Experimental Biology and Medicine, vol. 137, no. 2, pp. 696-701, 1971.

[7] H. Wang, G. J. Provan, and K. Helliwell, "HPLC determination of catechins in tea leaves and tea extracts using relative response factors," Food Chemistry, vol. 81, no. 2, pp. 307-312, 2003.

[8] H.-Y. Sohn, K. H. Son, C.-S. Kwon, G.-S. Kwon, and S. S. Kang, "Antimicrobial and cytotoxic activity of 18 prenylated flavonoids isolated from medicinal plants: Morus alba L., Morus mongolica Schneider, Broussnetia papyrifera (L.) Vent, Sophora flavescens Ait and Echinosophora koreensis Nakai," Phytomedicine, vol. 11, no. 7-8, pp. 666-672, 2004.

[9] S. Balakumar, S. Rajan, T. Thirunalasundari, and S. Jeeva, "Antifungal activity of Aegle marmelos (L.) Correa (Rutaceae) leaf extract on dermatophytes," Asian Pacific Journal of Tropical Biomedicine, vol. 1, no. 4, pp. 309-312, 2011.

[10] P. K. Mishra, R. Shukla, P. Singh, B. Prakash, and N. K. Dubey, "Antifungal and antiaflatoxigenic efficacy of Caesulia axillaris Roxb. essential oil against fungi deteriorating some herbal raw materials, and its antioxidant activity," Industrial Crops and Products, vol. 36, no. 1, pp. 74-80, 2012.

[11] O. Pancharoen, P. Tuntiwachwuttikul, W. C. Taylor, and K. Picker, "Triterpenoid glycosides from Schefflera lucantha," Phytochemistry, vol. 35, no. 4, pp. 987-992, 1994.

[12] D. Walters, B. Meurer-Grimes, and I. Rovira, "Antifungal activity of three spermidine conjugates," FEMS Microbiology Letters, vol. 201, no. 2, pp. 255-258, 2001.

[13] J. Li, F. Chen, and J. Luo, "GC-MS analysis of essential oil from the leaves of Psidium guajava," Journal of Chinese Medicinal Materials, vol. 22, no. 2, pp. 78-80, 1999.

[14] R. M. P. Gutiérrez, S. Mitchell, and R. V. Solis, "Psidium guajava: a review of its traditional uses, phytochemistry and pharmacology," Journal of Ethnopharmacology, vol. 117, no. 1, pp. $1-27,2008$.

[15] D. Vargas-Alvarez, M. Soto-Hernández, V. A. GonzálesHernández, E. M. Engleman, and Á. Martínez-Garza, "Kinetics of accumulation and distribution of flavonoids in Guava (Psidium guajava L.)," Agrociencia, vol. 40, no. 1, pp. 109-115, 2006.

[16] National Committee on Clinical Laboratory Standards, "Reference method for broth dilution antifungal susceptibility testing of yeasts; approved standard, 2nd ed," NCCLS Document M27A2, 2002.

[17] National Committee on Clinical Laboratory Standards, "Reference method for broth dilution antifungal susceptibility testing of filamentous fungi; approved standard," NCCLS Document M38-A, Wayne, Pa, USA, 2002.

[18] T. Mosmann, "Rapid colorimetric assay for cellular growth and survival: application to proliferation and cytotoxicity assays," Journal of Immunological Methods, vol. 65, no. 1-2, pp. 55-63, 1983.

[19] K. F. Chah, C. A. Eze, C. E. Emuelosi, and C. O. Esimone, "Antibacterial and wound healing properties of methanolic extracts of some Nigerian medicinal plants," Journal of Ethnopharmacology, vol. 104, no. 1-2, pp. 164-167, 2006.

[20] G. R. Prabu, A. Gnanamani, and S. Sadulla, "Guaijaverin-a plant flavonoid as potential antiplaque agent against Streptococcus mutans," Journal of Applied Microbiology, vol. 101, no. 2, pp. 487-495, 2006.

[21] H. Arima and G.-I. Danno, "Isolation of antimicrobial compounds from guava (Psidium guajava L.) and their structural elucidation," Bioscience, Biotechnology and Biochemistry, vol. 66, no. 8, pp. 1727-1730, 2002.

[22] S. García, M. Araiza, M. Gómez, and N. Heredia, "Inhibition of growth, enterotoxin production, and spore formation of Clostridium perfringens by extracts of medicinal plants," Journal of Food Protection, vol. 65, no. 10, pp. 1667-1669, 2002.

[23] J. Nguefack, V. Leth, P. H. Amvam Zollo, and S. B. Mathur, "Evaluation of five essential oils from aromatic plants of Cameroon for controlling food spoilage and mycotoxin producing fungi," 
International Journal of Food Microbiology, vol. 94, no. 3, pp. 329-334, 2004.

[24] B. M. Sundaram, C. Gopalakrishnan, and S. Subramanian, "Antimicrobial activities of Garcinia mangostana," Planta Medica, vol. 48, no. 1, pp. 59-60, 1983.

[25] M. Friedman, "Overview of antibacterial, antitoxin, antiviral, and antifungal activities of tea flavonoids and teas," Molecular Nutrition and Food Research, vol. 51, no. 1, pp. 116-134, 2007.

[26] T. Masuda, Y. Inaba, T. Maekawa et al., "Simple detection method of powerful antiradical compounds in the raw extract of plants and its application for the identification of antiradical plant constituents," Journal of Agricultural and Food Chemistry, vol. 51, no. 7, pp. 1831-1838, 2003. 


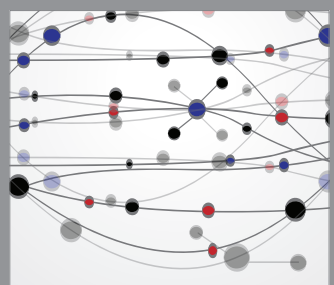

The Scientific World Journal
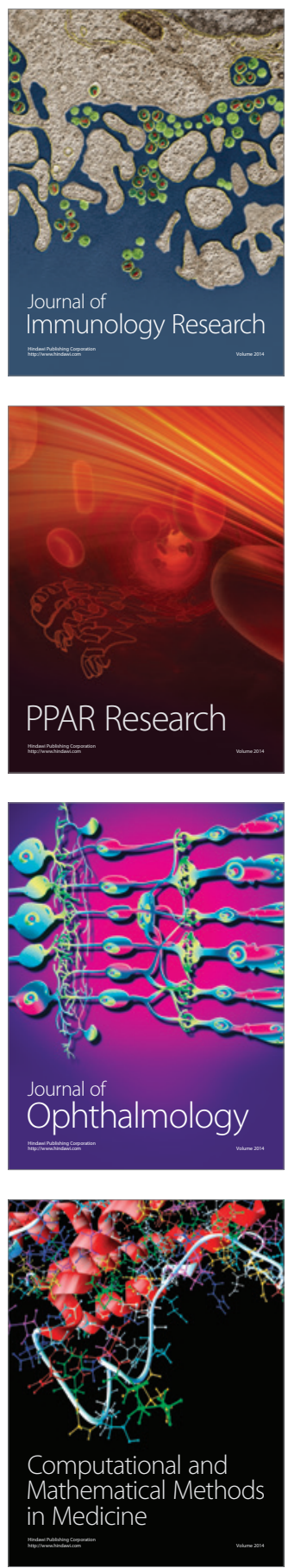

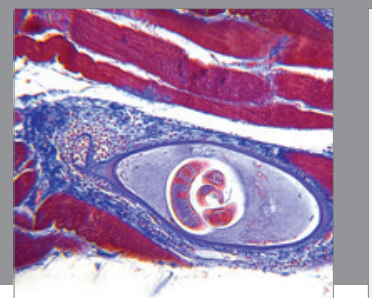

Gastroenterology

Research and Practice
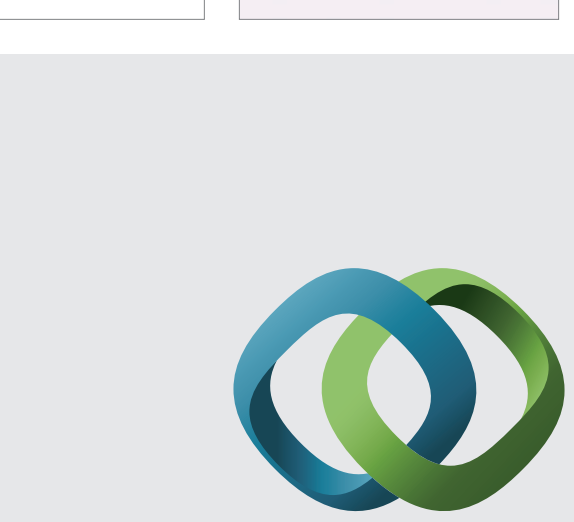

\section{Hindawi}

Submit your manuscripts at

http://www.hindawi.com
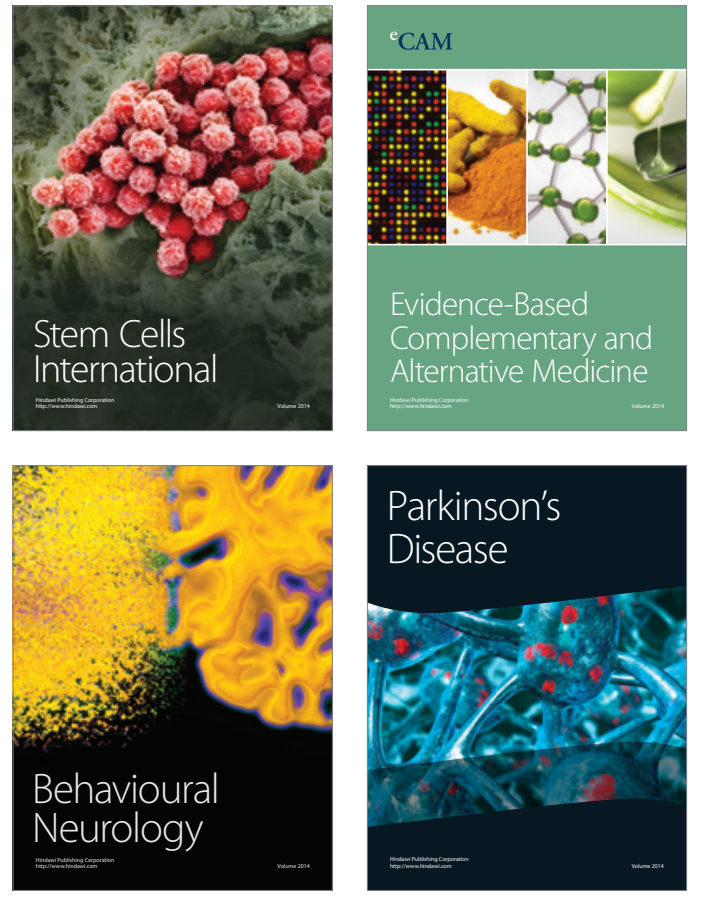
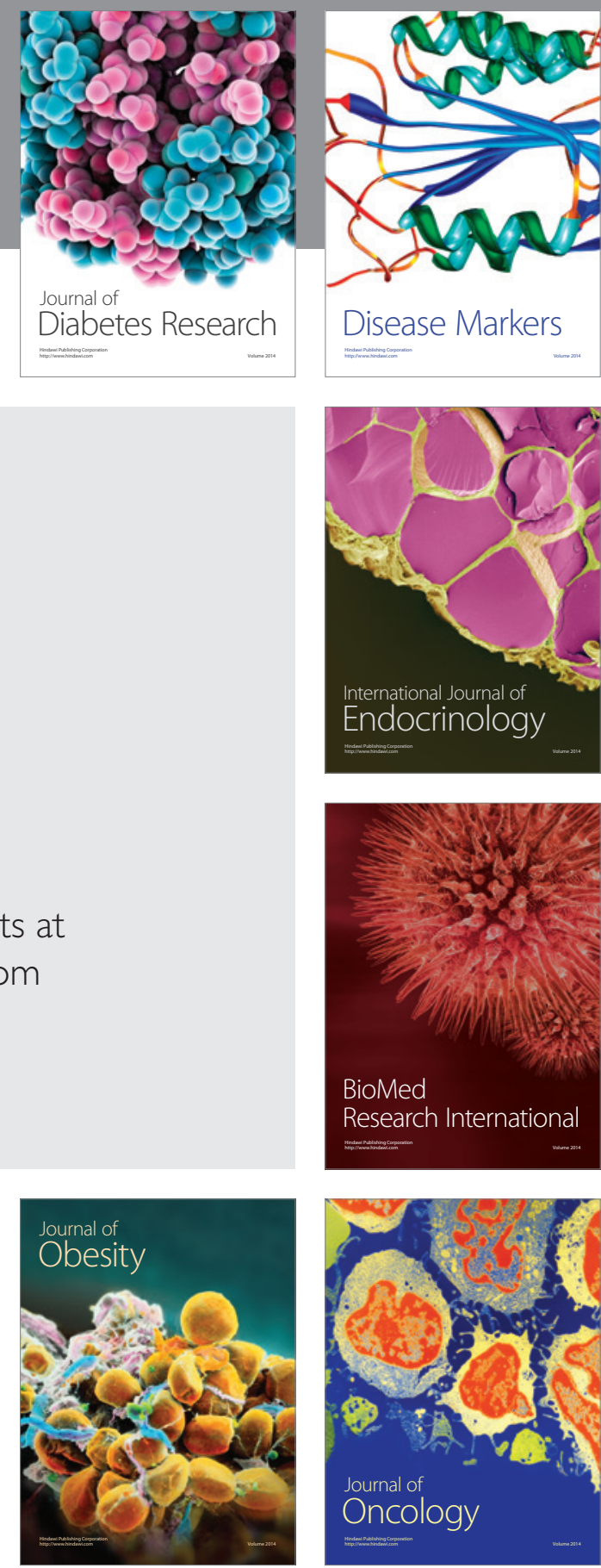

Disease Markers
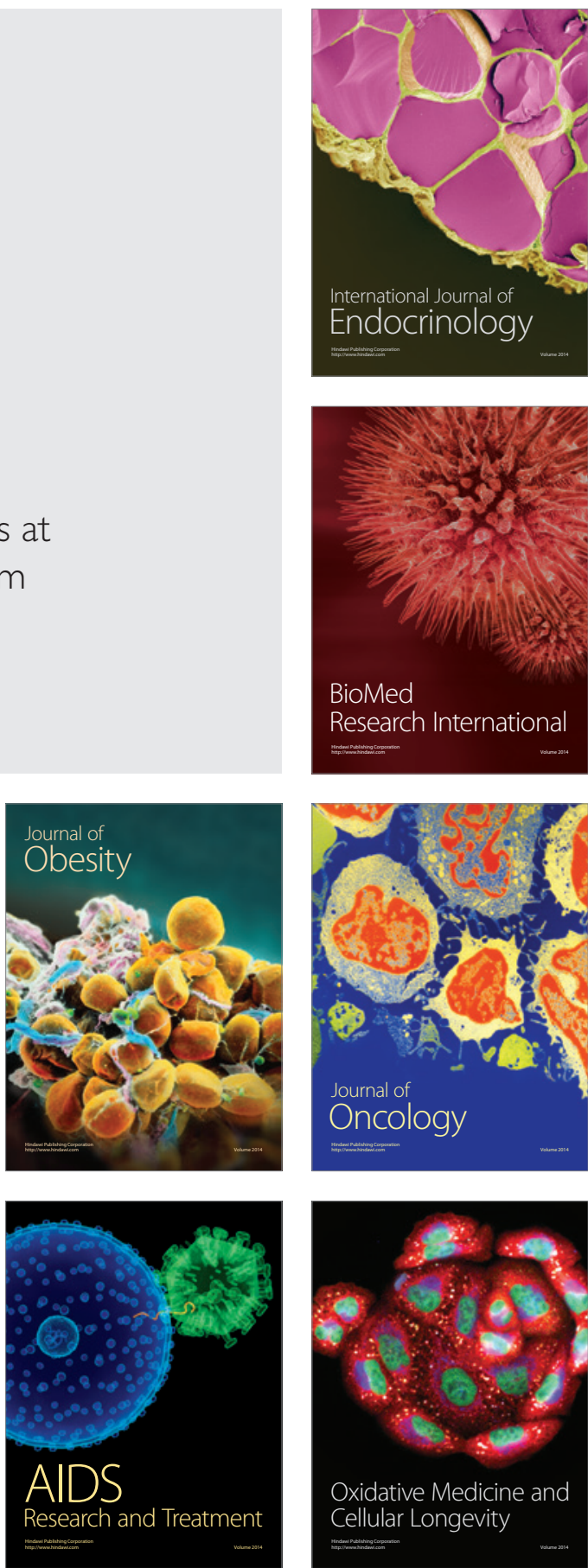